\title{
Back to basics: Pulse palpation to detect arrhythmia
}

\author{
Adolfo C. Cordero-Perez, Alejandro Gonzalez-Aquines, Alan I. Benitez-Alvarez, Javier Martínez-Moyano, \\ GECEN Researchers**, and Fernando Gongora-Rivera*
}

Department of Neurology, "Dr. José Eleuterio González” University Hospital and School of Medicine, Monterrey, Universidad Autónoma de Nuevo León, México

${ }^{*}$ GECEN researchers are listed as an annex at the end of the article.

\begin{abstract}
Objective: The objective of the study was to realize a population-based campaign and promote the detection of irregular pulses and stroke risk factors through pulse palpation. Materials and methods: We applied a standardized questionnaire with a guide to detect irregular radial pulses and stroke risk factors in rural and urban areas of Nuevo Leon, Mexico. Results: We analyzed 2387 surveys. Mean age was $47.7 \pm 17$ years, 1735 (73.4\%) were female, 26 (1.1\%) subjects had an irregular pulse, and the most prevalent cardiovascular risk factors were high blood pressure (38.5\%), active smoking status $(34.6 \%)$, active alcoholism status (26.9\%), diabetes (26.9\%), and heart disease (7.7\%). We found an association with the male gender $(p=0.007)$ and active smoking status $(p=0.003)$. Conclusion: An irregular pulse can be detected through pulse palpation, an economical and accessible clinical tool that can timely detect arrhythmias that increase the risk of a major cardiovascular event, including stroke.
\end{abstract}

Key words: Stroke. Arrhythmia. Irregular pulse. Mexico. Arterial pulse. Heart rate.

\section{Introduction}

Cardiac arrhythmias are abnormalities or perturbations in the normal activation or beating of the myocardium ${ }^{1}$. Atrial fibrillation (AF) is associated with significant morbidity, mortality, and socioeconomic burden, particularly from stroke and systemic thromboembolism². It is defined as a supraventricular tachyarrhythmia with uncoordinated atrial activation and ineffective atrial contraction ${ }^{3}$. Arrhythmias, specifically AF, considerably increase the risk of suffering a stroke ${ }^{4}$. The diagnosis of AF is made with an electrocardiogram study. However, this is difficult in rural areas due to limited resources ${ }^{3}$, thus making pulse palpation, a clinical and accessible part of the physical examination, a useful tool for the detection of an irregular pulse.
In the setting of World Stroke Day activities, our main objective was to promote the use of pulse palpation to detect arrhythmia, assessment of common stroke risk factors, and educate the general population about palpation of a regular pulse and defer an irregular pulse.

\section{Materials and methods}

We performed a cross-sectional observational study in the general population of Nuevo Leon, Mexico. Participants were included during the frame of the World Stroke Campaign (October 29). Selected subjects were those on transit in crowded public places of the urban and rural communities of Nuevo Leon, such as the central parks

\section{Correspondence:}

*Fernando Gongora-Rivera

E-mail: fernando.gongora@ @otmail.com
Available online: $18-06-2020$

Date of reception: 13-09-2019

Date of acceptance: 05-02-2020 DOI: 10.24875/RMU.20000125
Medicina Universitaria. 2020;22(2):61-64 www.medicinauniversitaria.org

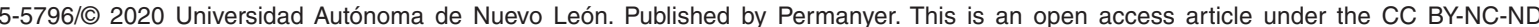
license (http://creativecommons.org/licenses/by-nc-nd/4.0/). 
Table 1. Four-step guide to measure and detect the radial pulse

1. Before starting, make sure you have rested in a sitting or lying position for a minimum of $10 \mathrm{~min}$, and not to have consumed any caffeine-containing beverage or smoked in the past $30 \mathrm{~min}$.

2. With the tip of your index and middle finger of one of your hands, search for your pulse in your wrist at the side of your thumb.

3. Count how many beats you have in a minute, you can use a watch.

4. Normally, your pulse should have a regular rhythm and be $<100 / \mathrm{min}$. If your pulse does not have a regular rhythm or the number of beats exceeds $100 /$ min, ask your doctor, since it could be a cardiac arrhythmia named atrial fibrillation, which can lead to a stroke.

of communities or shopping centers. Inclusion criteria were those who agreed to participate aged 18 or older who filled out the questionnaires completely. The sample size was calculated based on a population of 4.5 million inhabitants, according to national statistics, with a confidence interval of $95 \%$ and a margin of error of $2 \%$.

A questionnaire with sociodemographic variables and cardiovascular risk factors was applied to every participant. After completing the questionnaire, participants were taught how to measure their radial pulse. This was later confirmed by a primary care physician who was trained by one of the authors (fetal growth restriction) to carry out the survey precisely (Table 1). Pulse palpation has been reported as a reliable tool for the detection of irregular pulse and arrhythmias with high sensitivity (94\%) and specificity $(74 \%)$ to detect $\mathrm{AF}^{5}$. If an irregular pulse was confirmed, patients were referred to a second-level clinic for a diagnostic workout by cardiologists.

Categorical variables were analyzed using Chisquare $^{2}$ and Fisher's exact test; continuous variables used the Mann-Whitney U-test. Results were presented as percentages, means \pm standard deviation (SD), or as medians with their corresponding range as indicated. $\mathrm{P}<0.05$ was considered statistically significant. SPSS v23 was used for the analysis of the data.

The present study was approved by our Ethics Committee, with the number NR07-009, and verbal consent was obtained from the subjects.

\section{Results}

We collected 2599 questionnaires, of which 21 were excluded due to age and 191 were excluded due to incomplete data. Two thousand three hundred eighty-seven were analyzed. The mean age was $47.7 \pm 17$ years, $67 \%$ were $<55$ years old, and $1748(73.2 \%)$ were women. The most prevalent cardiovascular factors were high blood pressure 698 (29.6\%), diabetes mellitus $527(22.3 \%)$, and alcoholism 421(17.8\%). Mean body mass index was $28.6 \pm 5.6 \mathrm{~kg} / \mathrm{cm}^{2}$ and mean pulse $/$ min was $75 \pm 9$.

Irregular pulse was found in $26(1.1 \%)$ subjects. In the group with irregular pulse, mean age was $46.3 \pm 20.8$ and the most prevalent cardiovascular risk factors were high blood pressure $10(38.5 \%)$, active smoking status $9(34.6 \%)$, active alcoholism status $7(26.9 \%)$, diabetes $7(26.9 \%)$, and heart disease $2(7.7 \%)$. When comparing both groups, there was an association with the male gender $(p=0.007)$ and active smoking status $(p=0.003)$, table 2 shows comparisons between these and other risk factors.

\section{Discussion}

In our study, we report a prevalence of irregular pulse of $1.1 \%$ in the group with an irregular pulse with the characteristics of arrhythmia, such as those reported in a previous population-based study ${ }^{6}$. Further, we found an association with the male gender and the presence of heart disease. The prevalence of cardiovascular risk factors from our population is similar to that reported in large population studies from subjects with AF, such as the Atherosclerosis Risk in Communities Study and the Framingham studies ${ }^{7,8}$. There was not an increase in irregular pulse in older subjects (>60 years), which could be answered by the small proportion (23\%) of this age group.

Although pulse palpation is part of the physical examination, it has been replaced by electronic devices like the pulse oximeter, which calculates the mean heart rate but does not measure the rhythm of the pulse. Therefore, we encourage health practitioners to foster the use of this free and accessible clinical tool for the detection of irregular pulse and heart arrhythmias, including AF.

Our study presented diverse limitations, and follow-up was not made personally because subjects with an irregular pulse were referred to their second-level clinic to get an electrical heart evaluation, as most of our population 
Table 2. Regular pulse versus irregular pulse

\begin{tabular}{|c|c|c|c|c|}
\hline \multicolumn{3}{|l|}{ Characteristics } & \multirow{2}{*}{$\begin{array}{c}\text { Regular pulse ( } \mathbf{n}=\mathbf{2 3 6 1}) \text { no. (\%) } \\
\mathrm{OR}, 95 \% \mathrm{Cl}\end{array}$} & \multirow{2}{*}{$\begin{array}{c}\text { Irregular pulse }(\mathbf{n}=26) \text { no. }(\%) \\
p\end{array}$} \\
\hline Age $($ mean $\pm S D)$ & $47.7 \pm 17.1$ & $46.3 \pm 20.8$ & & \\
\hline Gender, male & $626(26.5)$ & $13(50)$ & - & 0.542 \\
\hline Current smoker & $302(12.8)$ & $9(34.6)$ & $2.7(1.2-6.0)$ & 0,007 \\
\hline Alcohol status & $421(17.8)$ & $7(26.9)$ & $3.7(1.6-8.3)$ & 0.003 \\
\hline Diabetes mellitus & $527(22.3)$ & $7(26.9)$ & - & 0.345 \\
\hline Hypertension & $698(29.6)$ & $10(38.5)$ & - & 0.575 \\
\hline Hyperthyroidism & $45(1.9)$ & $0(0)$ & - & 0.323 \\
\hline Previous AMI & $45(1.9)$ & $2(7.7)$ & - & 1.000 \\
\hline Previous stroke & $26(1.1)$ & $1(3.8)$ & - & 0.161 \\
\hline \multirow[t]{2}{*}{ BMI (mean \pm SD) } & $28.65 \pm 5.6$ & $29.22 \pm 5.7$ & - & 0.701 \\
\hline & & & - & 0.614 \\
\hline
\end{tabular}

AMI: acute myocardial infarction; BMI: body mass index; OR: odds ratio; $\mathrm{Cl}$ : confidence interval.

was affiliated to the Seguro Popular (governmental health program) and a reference note was needed to continue with the adequate management for probable arrhythmia. Furthermore, our study was comprised mostly of women. Therefore, the generalization of our results was limited to the population with characteristics similar to ours. However, some of our strengths are the representation of the population of the state of Nuevo Leon and that this is the first study including both rural and urban subjects. Further studies confirming the diagnosis of AF with electronic heart rhythm monitoring are needed.

\section{Conclusion}

Our results provide evidence that detecting an irregular pulse during the physical examination could be the first step to detect heart arrhythmias, including AF. General practitioners, especially those in rural areas, should consider going back to the basics and making a great impact in their patients' lives by detecting probable AF to reduce the burden of $A F$, and consequently, of stroke. The population can economically be able to measure their heart rate, differentiating a regular pulse from an irregular one, as well as educating the population about the cardiovascular risk factors of ischemic stroke.

\section{Acknowledgments}

The authors acknowledge to the Secretary of Health of the State of Nuevo Leon for its contribution to the distribution and application of the surveys in this study.

\section{Conflicts of interest}

The authors declare not having any conflicts of interest.

\section{Ethical disclosures}

Protection of human and animal subjects. The authors declare that no experiments were performed on humans or animals for this study.

Confidentiality of data. The authors declare that they have followed the protocols of their work center on the publication of patient data.

Right to privacy and informed consent. The authors have obtained the written informed consent of the patients or subjects mentioned in the article. The corresponding author is in possession of this document.

\section{Annex1: GECEN researchers}

Lizeth Gonzalez-Garza, Kelly D Garza-Davila, Luis A Ramirez-Martinez, Jorge G Perez-Vazquez, Daniela Ortiz-Zacarias, Jonathan Camacho-Hernandez, Silvia Barrera-Barrera y Yesica Sauceda-Ostos.

\section{References}

1. Fu DG. Cardiac arrhythmias: diagnosis, symptoms, and treatments. Cell Biochem Biophys. 2015;73:291-6. 
2. Chao TF, Lip GY, Liu CJ, Lin YJ, Chang SL, Lo LW, et al. Relationship of aging and incident comorbidities to stroke risk in patients with atria fibrillation. J Am Coll Cardiol. 2018;71:122-32.

3. January CT, Wann LS, Alpert JS, Calkins H, Cigarroa JE, Cleveland JC Jr., et al. 2014 AHA/ACC/HRS guideline for the management of patients with atrial fibrillation: a report of the American college of cardiology/American heart association task force on practice guidelines and the heart rhythm society. J Am Coll Cardiol. 2014;64:e1-76.

4. Andrew NE, Thrift AG, Cadilhac DA. The prevalence, impact and economic implications of atrial fibrillation in stroke: what progress has been made? Neuroepidemiology. 2013;40:227-39.
5. Cooke G, Doust J, Sanders S. Is pulse palpation helpful in detecting atrial fibrillation? A systematic review. J Fam Pract. 2006;55:130-4.

6. Khurshid S, Choi SH, Weng LC, Wang EY, Trinquart L, Benjamin EJ, et al. Frequency of cardiac rhythm abnormalities in a half million adults. Circ Arrhythmia Electrophysiol. 2018;11:e006273.

7. Huxley RR, Lopez FL, Folsom AR, Agarwal SK, Loehr LR, Soliman EZ, et al. Absolute and attributable risks of atrial fibrillation in relation to optimal and borderline risk factors: the atherosclerosis risk in communities (ARIC) study. Circulation. 2011;123:1501-8.

8. Benjamin EJ, Levy D, Vaziri SM, D’Agostino RB, Belanger AJ, Wolf PA. Independent risk factors for atrial fibrillation in a population-based cohort. The Framingham heart study. JAMA. 1994;271:840-4. 